\title{
Inhaltsverzeichnis
}

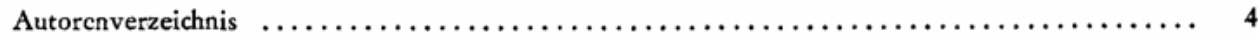

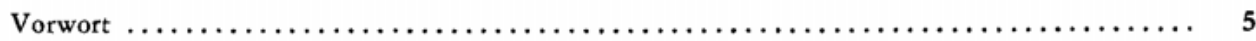

\section{Fritbjof Kunz}

Zur Erhöhung der Wirksamkeit des sozialistischen Arbeitsrechts bei der Entfaltung der entscheidenden Triebkraft der entwickelten sozialistischen Gesellschaft zur Durchsetzung des wissen-

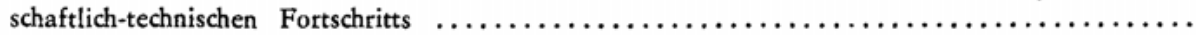

Siegfried Seidel

Zur Rolle des Arbeitsrechts bei der Durchsetzung des wissenschaftlich-technischen Fortschritts

Gottfried Bauer / Hans-Georg Krey

Der Akademie-Industrie-Komplex „Arzneimittelforschung“ im Blick rechtswissenschaftlicher Frage-

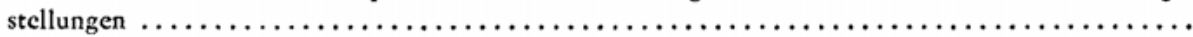

Dietmar Seidel

Möglichkeiten und Grenzen des sozialistischen Rechts bei der Stimulierung schöpferischer Arbeit auf dem Gebiet des wissenschaftlich-technischen Fortschritts $\ldots \ldots \ldots \ldots \ldots \ldots \ldots \ldots \ldots$

Ernst Winklbauer

Zur Erhöhung der Wirksamkeit des Neuerer- und Erfinderrechts der DDR bei der Entfaltung

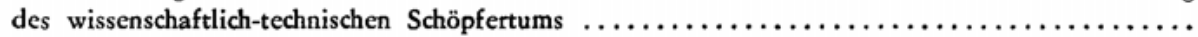

Gerbard Feige

Das wissenschaftlich-technische Ergebnis als Maß des wissenschaftlich-technischen Fortschritts ...

Hans Leger

$\mathrm{Zu}$ cinigen aktuellen Fragen der weiteren Beschleunigung des wissenschaftlich-technischen Fortschritts

Heinrich Seickert

$\mathrm{Zu}$ einigen das sozialistische Recht betreffenden Problemen der Beschleunigung des wissenschaftlich-technischen Fortschritts aus der Sicht der wissenschaftstheoretischen Forschung .........

Richard Häbnert

Zur Rolle des LPG-Rechts bei der Durchsetzung des wissenschaftlich-technischen Fortschritts in der Landwirtschaft 